\title{
Auxiliary subsystems of a General-Purpose IGBT Stack for high-performance laboratory power converters
}

\author{
ANIL KUMAR ADAPA*, D VENKATRAMANAN and VINOD JOHN \\ Department of Electrical Engineering, Indian Institute of Science, Bangalore 560012, India \\ e-mail: aniladapa@ee.iisc.ernet.in; venkat86ram@ee.iisc.ernet.in; vjohn@ee.iisc.ernet.in
}

MS received 15 March 2016; accepted 16 November 2016

\begin{abstract}
A PWM converter is the prime component in many power electronic applications such as static UPS, electric motor drives, power quality conditioners and renewable-energy-based power generation systems. While there are a number of computer simulation tools available today for studying power electronic systems, the value added by the experience of building a power converter and controlling it to function as desired is unparalleled. A student, in the process, not only understands power electronic concepts better, but also gains insights into other essential engineering aspects of auxiliary subsystems such as start-up, sensing, protection, circuit layout design, mechanical arrangement and system integration. Higher levels of protection features are critical for the converters used in a laboratory environment, as advanced protection schemes could prevent unanticipated failures occurring during the course of research. This paper presents a laboratory-built GeneralPurpose IGBT Stack (GPIS), which facilitates students to practically realize different power converter topologies. Essential subsystems for a complete power converter system is presented covering details of semiconductor device driving, sensing circuit, protection mechanism, system start-up, relaying and critical PCB layout design, followed by a brief comparison to commercially available IGBT stacks. The results show the high performance that can be obtained by the GPIS converter.
\end{abstract}

Keywords. IGBT Stack; auxiliary subsystems; pre-charge circuit; forced-air cooling; system start-up; dc-link capacitor; protection mechanism; IGBT de-saturation; dead-time; gate drive.

\section{Introduction}

IGBT-based power electronic converters are widely employed today in a variety of power conversion applications such as adjustable speed motor drives, off-grid or grid-tied renewable-energy-based power generation systems, power quality conditioning systems, consumer electronics and lighting system power supplies [1-5]. Admittedly, a PWM power converter is a critical subsystem in any power electronic system. Owing to efficiency considerations, for low-voltage (below $200 \mathrm{~V}$ ) high-current systems, typically MOSFET-based designs are preferred and for systems with voltages above $400 \mathrm{~V}$ and high current, IGBTs are invariably employed [6]. A variety of IGBT-based power stacks are available today commercially. Although they house a number of desirable system level features, they are typically available only for power level above $50 \mathrm{kVA}$ [7-9]. Also, numerous computer simulation tools are available today and are widely used to perform simulation studies on power electronic systems.

*For correspondence
While there is a great deal of published literature on design methods specific to various subsystems of a power electronic system such as power converter topologies, control architecture, filters and PWM techniques $[5,10-14]$, publications that actually deal with design aspects of essential auxiliary circuits, which would aid a graduate level student to build a PWM power converter in laboratory, are rather limited.

The goal of this work therefore is to enable laboratory prototyping of a power converter system in the form of a General-Purpose IGBT Stack (GPIS). The focus is particularly laid on the power converter balance of system, which includes gate drive design for semiconductor devices, protection mechanisms, start-up sequence and self-test for fault diagnosis. As an example, the design details of a discrete-IGBT-based GPIS developed in the laboratory are presented. Such a generic design is helpful in realizing a variety of power circuit topologies as elucidated in [15], and the exercise of building a GPIS would greatly enhance hardware design and troubleshooting skills of a student working on the power electronics technology. The results obtained from the power converter hardware show the high performance that can be obtained by the GPIS converter. 


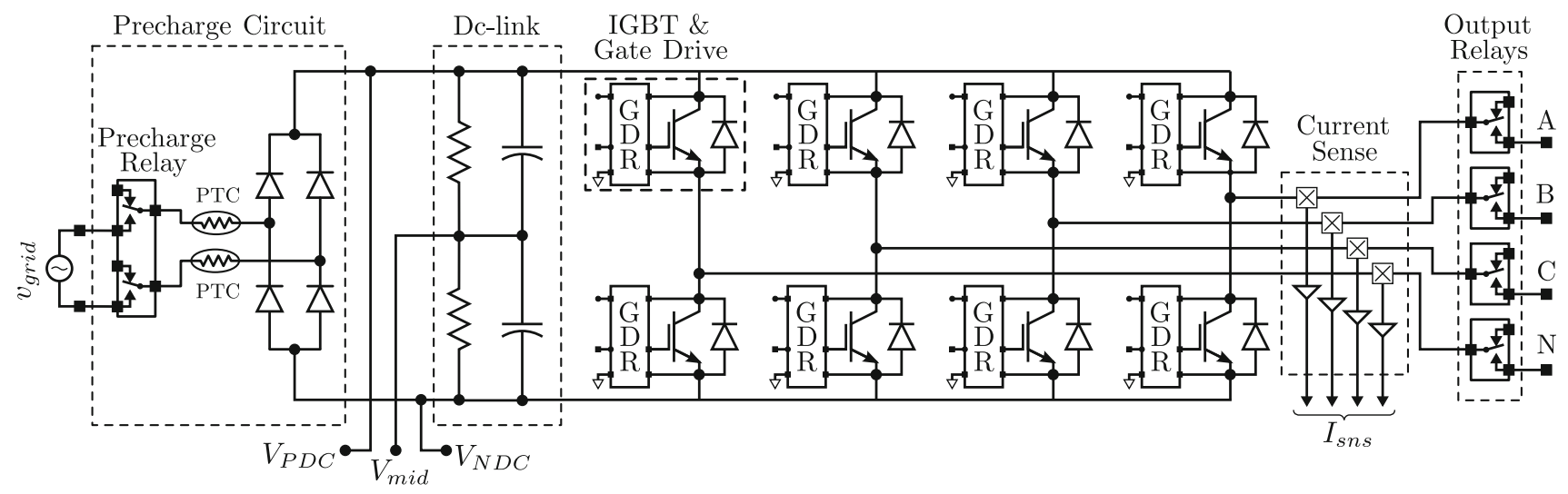

Figure 1. Power circuit configuration of two-level three-phase four leg converter.

\section{Power converter auxiliary subsystems}

The presented GPIS is a two-level three-phase four-leg power converter, which uses state-of-the-art discrete IGBTs and other components. The circuit schematic and system specifications are shown in figure 1 and table 1, respectively. The details of the power circuit design is discussed in $[16,17]$. The various subsystems of GPIS include an onboard gate-driver, gate drive power supply, sensor card and protection, dead-time and annunciation (PDA) card, in the form of auxiliary cards that are explained in detail below.

\subsection{Gate-drive circuitry}

A gate driver is an integral part of any power converter system. It converts logic or signal level commands from an external digital signal controller (DSC) or analog controller to appropriate power level signals capable of reliably turning on and off the power semiconductor device. Most often, one or more power supplies isolated from control circuitry are required for driving the devices.

Another desirable feature of a gate driver is to protect the device against short-circuit faults by sensing $V_{C E s a t}$ and by detecting switch de-saturation. Commercially available gate-drive cards, in addition to this, offer a few other attractive features such as soft device turn-off after fault detection, under-voltage lockout and fault-detection feedback signal to DSC $[18,19]$. A simple method to obtain isolation and other desirable features using off-the-shelf driver ICs is reported in literature [18]. In this work, a similar method is adopted with an ACPL-339J gate-driver IC [20], which is capable of driving a MOSFET-based current booster. Also, the design in this work is modular, compact and suited for individual discrete devices. A highfrequency half-bridge-based converter is designed for powering the gate-drive cards, which drive eight discrete devices of GPIS.

The gate driver and half-bridge power supply configuration presented in [17] have been implemented.
Table 1. GPIS power converter ratings.

\begin{tabular}{lc}
\hline Item & Value \\
\hline Power & $25 \mathrm{kVA}$ \\
Dc bus voltage $V_{d c}$ & $800 \mathrm{~V}$ \\
Output voltage $(l-l)$ & $400 \mathrm{~V}$ \\
Output current (RMS) & $36 \mathrm{~A}$ \\
Nominal power factor & $\mathrm{UPF}$ \\
Nominal modulation index $m_{a}$ & 0.9 \\
Switching frequency $f_{s w}$ & $7.5 \mathrm{kHz}$ \\
\hline
\end{tabular}

Figure 2a shows a block schematic of gate drivers and half-bridge power supply arrangement. The corresponding assembled PCB card is shown in figure $2 \mathrm{~b}$. In this design, separate turn-on and turn-off gate resistances are used for better control of switching times, along with a TVS diode (SMBJ13CA), which is present between the gate and source to limit voltage excursions to $\pm 15 \mathrm{~V}$. Also, provision to a place ferrite-bead and additional gate-source capacitance is provided to appropriately dampen excessive ringing, if any. A tight physical layout of on-board drive circuit components is utilized as this plays a decisive role in determining the parasitics and hence the nature of switching transitions. The parasitic inductance between the switching device and the gate driver is much smaller in the suggested layout than what is encountered in typical IGBT module gate drivers, which employ wire leads and extension connectors.

Figure 3 shows the device switching characteristics of the developed GPIS with the designed gate driver. Smooth turn-on and turn-off characteristics indicate lower parasitics on the board. Short-circuit test is carried out by giving a turn-on command to the bottom device driver with a shortcircuited top device. Figure 4 shows the soft turn-off functionality of the gate driver under shoot-through conditions. This ensures that the converter is well protected even if some accidental short circuit happens in the converter. 


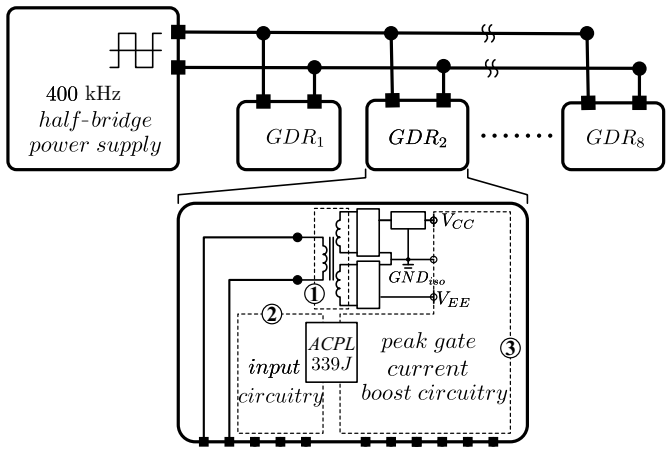

(a)

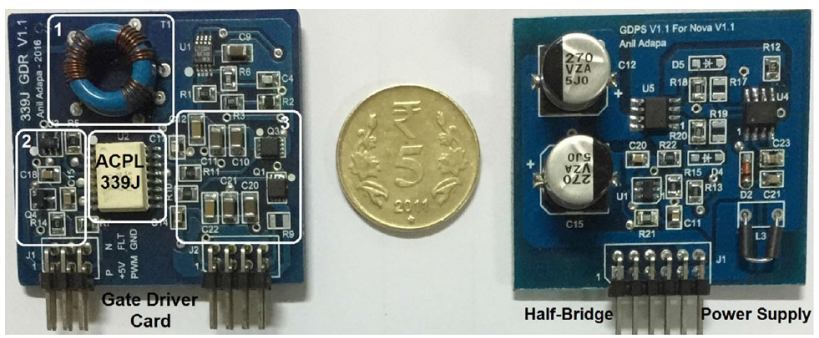

(b)

Figure 2. Gate drive configuration of the GPIS. (a) Block schematic of the gate drive circuit. (b) Assembled gate-drive circuit and half-bridge power supply PCB hardware, showing (1) isolation transformer, (2) input circuitry and (3) output gate current boost circuit.

\subsection{Protection mechanism}

A generalized protection card that releases all PWM signals from DSC to the power converter and corrects inadequate dead-time, if any, to the preset value is presented in [21]. It also protects the power converter by shutting off the PWM pulses in the event of a fault. Such an interface card reduces the burden on the DSC by relieving it of the duty of providing protection and thus creates additional room for control algorithm implementation.

In this work, an advanced PDA card is employed, as shown in figure 5. It uses a Lattice FPGA MACHXO2-
1200HC4TG100I as the controller and is programmed with VHDL for digital logic implementation. This card monitors key sensor signals and reports fault in case any quantity exceeds the preset limits. Various features of this card are listed below.

1. De-saturation fault detection for eight IGBTs and fault reporting.

2. Programmable dead-time lockout for four legs while facilitating independent and/or complementary control of the two devices of each leg.

3. Programmable minimum pulse width suppression.

4. Over-temperature detection of the heat-sink and fault reporting.

5. Serial communication with the DSC and with other PDA cards, if any.

6. Over-current $(\mathrm{OC})$ sense for four current signals, overvoltage (OV) and under-voltage (UV) sense for two dclink voltages.

7. A push-button or toggle switch feature to manually power on or shut off the power converter.

8. DSC-based enable-signal to allow or inhibit all PWM signals as required.

9. A manual and a software-based reset signal to resume converter operation after fault clearance.

10. Fault indication to user through LEDs.

11. Fan fault indication to DSC.

Item 5 in this list allows the operation of multiple converters in parallel or in other configuration. Such converters would be able to coordinate their fault protection by using the communication between PD cards.

The finite state-machines (FSMs) implemented in FPGA representing the key functionalities of the PDA card are shown in figure 6 . The top level functional state machine shown in figure 6a has four states, namely PWR on, Idle, Ready and Normal. After stabilization of power supply to the FPGA, FSM enters the Idle state and monitors for the converter turn-on and reset commands, which leads to change of state from Idle to Ready. A logic high " EN DSC" is required for the FSM to enter the Normal state,

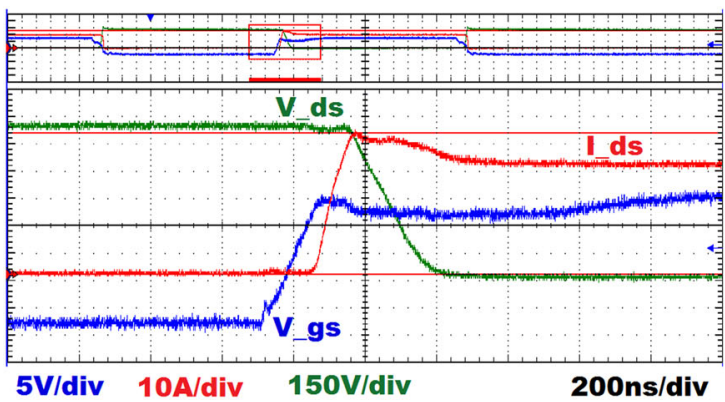

(a)

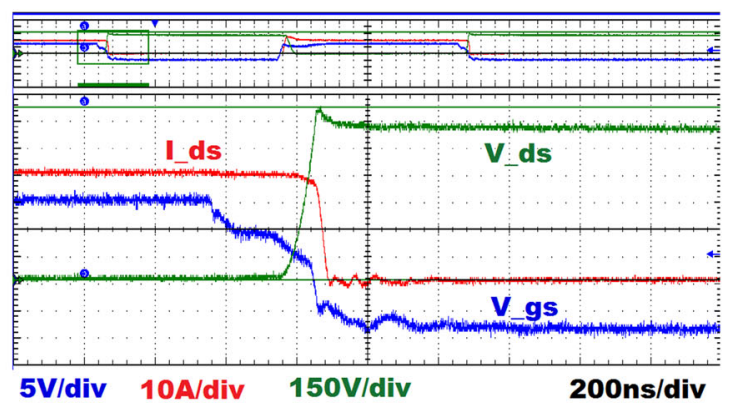

(b)

Figure 3. Switching characteristics of the IKW40N1200H3 IGBT at $800 \mathrm{~V}$ dc link and 40 A current with the designed MOSFET buffered gate drive card. (a) Turn-on characteristics. (b) Turn-off characteristics. 


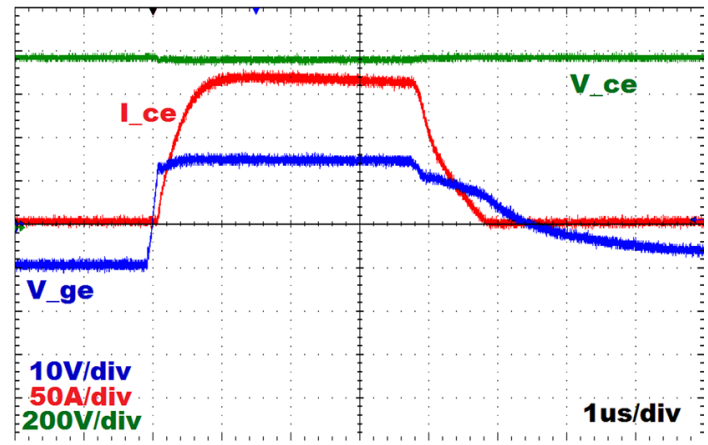

Figure 4. Short-circuit test of the IKW40N1200H3 IGBT with the designed MOSFET buffered gate drive card.

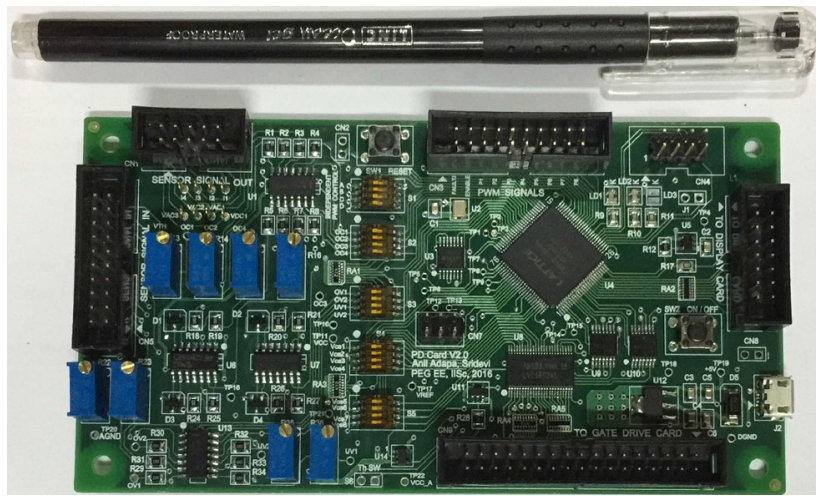

Figure 5. Assembled PCB of PDA card.

which allows PWM signals to the gate drive cards. All the critical fault signatures are monitored by the FPGA and registration of any fault brings the FSM to Idle state, which inhibits PWM signals to protect the converter. Registered fault information is indicated to the user through a LEDbased display card. Users can resume the converter operation by asserting the active low reset through the DSC or manual reset, after clearing the corresponding fault. This comprehensive protection scheme ensures that any potential damage to the power converter is avoided even when used by a novice without significant prior hardware experience.

Practical semiconductor switches take a finite amount of time to turn on and turn off. Simultaneous turn-on and turnoff of the complementary devices of a converter leg lead to cross-conduction for a short time period. To avoid crossconduction, after turn-off of a particular device, turn-on pulse to the complementary device is delayed by a short period, also called as dead-time. Higher dead-time results in higher distortion in line currents, especially when the converter is operated in open loop or without high bandwidth current controller [22]. Hence, selection of appropriate dead-time is a key factor. An example for choice of dead-time with Infineon IGBT IKW40N120H3 and ACPL 339J gate driver IC is presented later.

\section{1a Choice of dead-time:}

- Obtain device turn-off $\left(t_{o f f}\right)$ and turn-on $\left(t_{o n}\right)$ times from data-sheet at $150^{\circ} \mathrm{C}$. In the present case, turn-off and turn-on times are 402 and $78 \mathrm{~ns}$, respectively [23].

- Calculate difference of turn-off and turn-on times, and obtain the maximum propagation delay mismatch between (any two) gate driver ICs from data-sheet [20]. In this instance, the device transition time and propagation delay differences are 324 and $200 \mathrm{~ns}$, respectively.

- Hence the required minimum dead-time period is 524 ns. Considering a factor of safety of $15 \%$, dead-time is chosen to be $600 \mathrm{~ns}$.

Dead-time logic is represented as FSM in figure $6 \mathrm{~b}$ with four states and the corresponding output PWM signals. The FSM can continue in any of the three states Top ON, Bot $O N$ and $O F F$ as long as the DSC gives the corresponding PWM signals and it does not respond to the illegal input like turning-on both top and bottom devices. When the DSC tries to switch from the states Top ON or Bot ON, FSM enters in the state DT Lock and waits for the preprogrammed dead-time period without receiving any

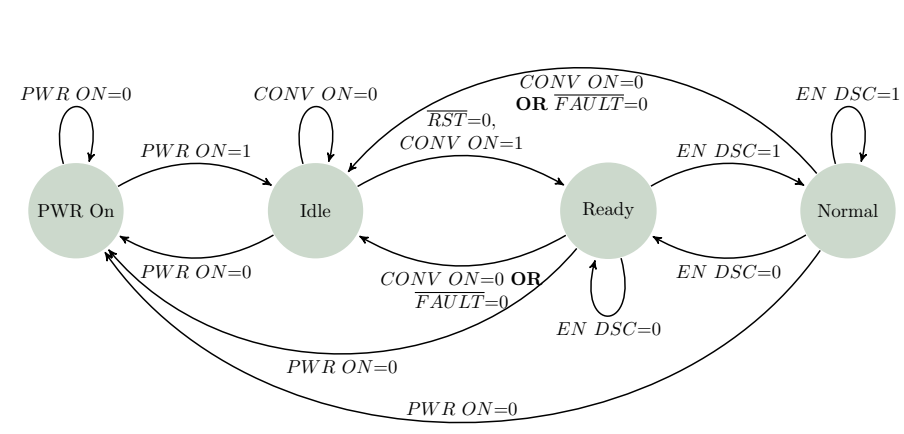

(a)

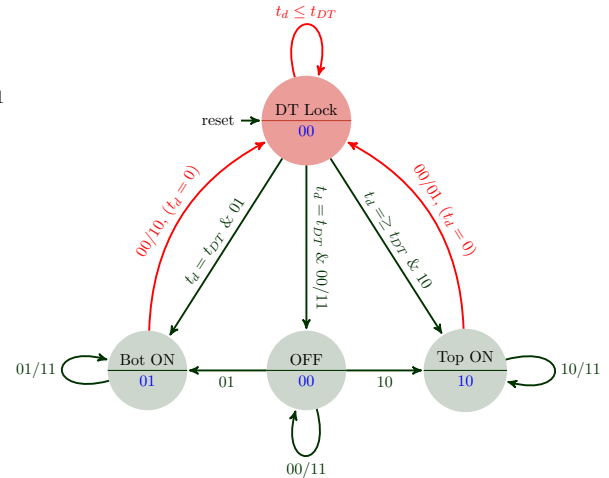

(b)

Figure 6. Finite state machine implementation of digital logic in PDA card. (a) Top-level digital logic in PDA card. (b) Dead-time logic. 
signals from DSC for this period. During the dead-time lock out state (DT Lock) the FSM turns off both the PWM signals to ensure minimum dead-time.

The PWM pulses, with turn-on or turn-off time considerable to the dead-time, have insignificant contribution to the resultant pole voltage in a switching cycle [21]. These pulses cause only additional switching losses and hence such PWM pulses are filtered out digitally with the designed PDA card. Also this serves as a noise filter. In the presented work, a minimum pulse width of $500 \mathrm{~ns}$ is employed, which can be programmed to make it suitable with other higher rated IGBTs.

Figure 7 shows the PWM pulses $S_{A(\text { out })}$ and $\bar{S}_{A(\text { out })}$ released by the PDA card in response to test PWM input signals $S_{A(i n)}$ and $\bar{S}_{A(i n)}$. In the figure, different zones marked are as follows:

(a) PDA card releasing the PWM pulses that already possess requisite dead-time,

(b) Pre-programed dead-time added by the PDA card to those PWM pulses that lack dead-time,

(c) PDA card filtering pulses of duration below the allowed minimum,

(d) independent control of complementary PWM signals and

(e) blocking of inappropriate PWM signals.

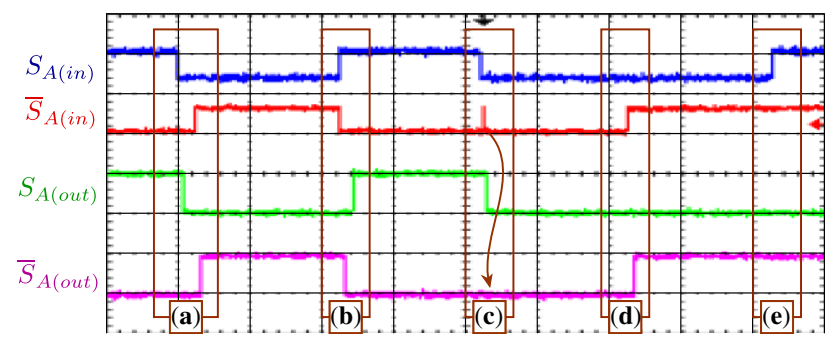

Figure 7. Functional test of dead-time FSM using test input signals, $S_{A(\text { in })}$ and $\bar{S}_{A(i n)}$. All channels are rated $5 \mathrm{~V} / \mathrm{div}$ and time $5 \mu \mathrm{s} / \mathrm{div}$.
This experiment verifies that the digital protection logic incorporated.

\subsection{Sensing circuit}

A non-isolated sensor card capable of sensing up to five voltages, four currents and six temperature quantities is employed in this work. The card is designed to measure ac or dc quantities rendering a measuring range of $\pm 660 \mathrm{~V}$ for three voltage channels, $\pm 1200 \mathrm{~V}$ for the remaining two, \pm 80 A for current using HLSR-32P open-loop Hall sensors and $0-150^{\circ} \mathrm{C}$ for temperature using thermistors. Adequate filtering is provided on board and the sensed signals are level-shifted suitably, using resistive dividers and a reference voltage, to form unipolar output signals falling in the range of $0-3 \mathrm{~V}$. The $3 \mathrm{~V}$ level-shifting reference voltage is derived from TL431 voltage regulator. The sensor card can thus be directly interfaced to a modern external DSC that works at $3.3 \mathrm{~V}$. A differential-amplifier-based non-isolated input stage, using a TL074BC op-amp is employed for voltage sensing, followed by a level-shifting circuit as shown in figure 8 . Since current and temperature sensors employed in the present design already generate unipolar outputs, only buffers and filters on-board are used for the same. The use of differential voltage sensors and isolated current sensors ensures that the DSC can be safely operated with its own ground reference while ensuring signal integrity.

\subsection{Relaying}

The four-pole leg outputs of the power converter are taken through PCB-mounted SPDT power relays (832HAWP-1CF-S) that are independently controllable through the DSC. Once self-test routine check is complete, which is explained in section 3, appropriate relays depending on the desired power circuit topology are closed. A separate DPDT relay is present for dc-link pre-charge as explained in section 3 .

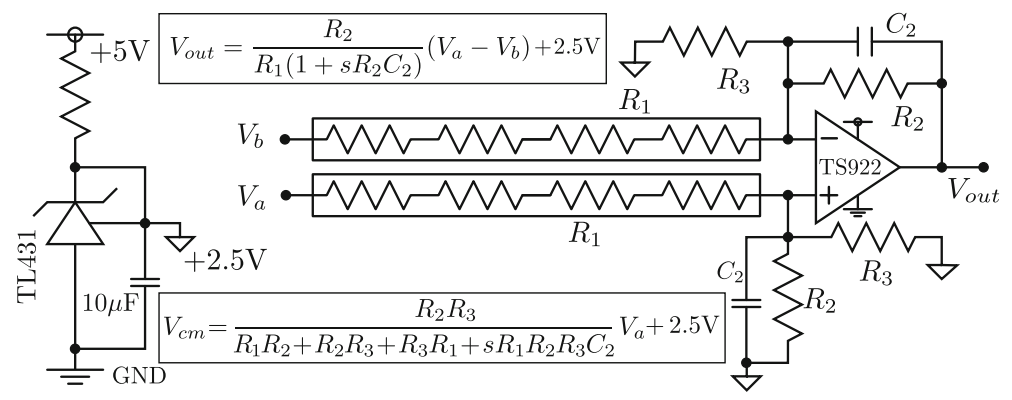

(a)

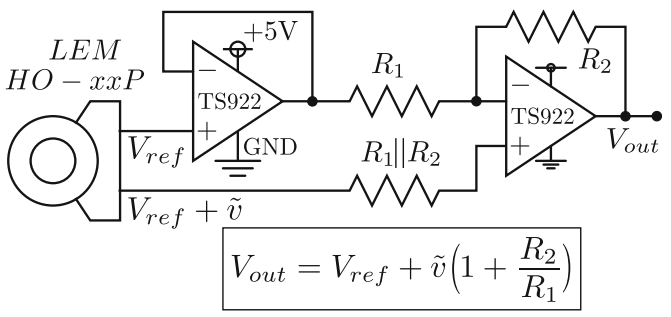

(b)

Figure 8. Measurement interface using (a) voltage-sense and (b) current-sense circuitry. 


\section{Start-up sequence and self-test}

In order to pre-charge the dc-link, a single-phase full bridge diode rectifier configuration is used together with a Positive Temperature Co-efficient (PTC) thermistor and a DPDT relay, as shown in figure 1 . The relay when closed connects the output terminals to Normally Open (NO) input terminals, and thus connects the diode bridge to the grid voltage. The grid may either be in line-line configuration for threephase systems or line-neutral configuration for singlephase systems. The number of PTC thermistors required, $N$, is obtained using the worst case scenario of precharging dc bus capacitance $C_{d c}$ with a dc source of $V_{d c}$. Total energy dissipated in the thermistor during precharge equals the amount of energy suppled to the dc link capacitors as given in (1). This dissipated energy increases the body temperature of PTC, and after crossing reference or knee temperature $T_{r e f}$, the resistance increases sharply. The dc link capacitance is $1.23 \mathrm{mF}$, for the selected PTC thermistor, B59412C1130B070 from TDK, has heat capacity $C_{t h}$ of 2.1 $\mathrm{J} / \mathrm{K}$ and $T_{\text {ref }}$ of $130^{\circ} \mathrm{C}$ [24]. Here, maximum dc link precharge voltage of $650 \mathrm{~V}$ and maximum ambient temperature, $T_{A_{\max }}$, of $60^{\circ} \mathrm{C}$ are considered for proper functioning of the precharge circuit even with a closed cabinet.

$$
N C_{t h}\left(T_{r e f}-T_{A_{\max }}\right)=\frac{1}{2} C_{d c} V_{d c}^{2}
$$

From (1) the obtained $N$ is 1.768 ; hence, two thermistors are added to two poles of the relay. For the selected part, minimum resistance is $63 \Omega$. Hence, initial peak current during precharge is $5.16 \mathrm{~A}$ at line-line voltage of $460 \mathrm{~V}$. Ratings of the precharge relay and diode bridge rectifier are selected to cater to this maximum peak current, which reduces gradually for the subsequent cycles due to increase in capacitor voltage. Figure 9 shows the experimental result of $\mathrm{dc}$ bus pre-charging in the line-line configuration drawing the peaky current with a maximum value of $3.2 \mathrm{~A}$.

A self-test may be performed to diagnose faults either in dc-link capacitors or semiconductor devices before the

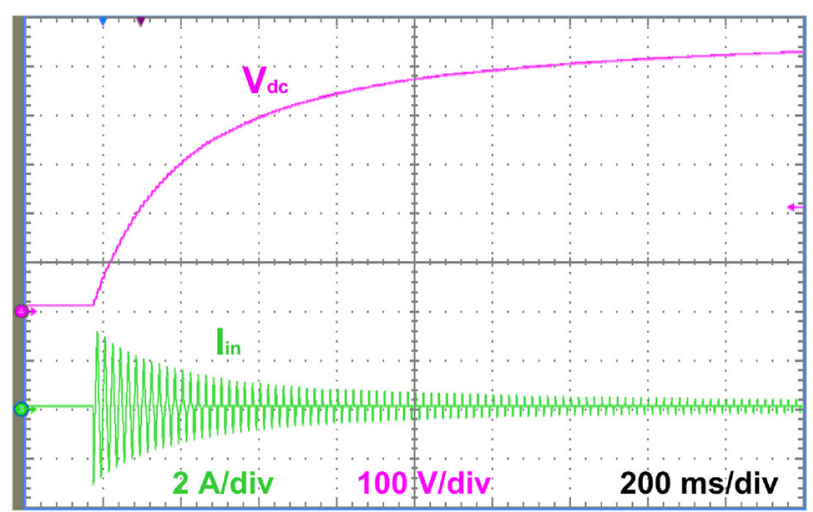

Figure 9. Precharging of the dc link with line-line grid voltage. closure of the output relays. The dc-link charging timeconstant may be used as an indicator of defects in the dclink capacitors. Time-constant is determined with known values of PTC resistance and chosen capacitance. By measuring the time for the dc-link to charge to a preset value, it is possible to diagnose a fault, if any, in the dclink. PTC resistors inherently provide fault tolerance by limiting the current at steady state to safe values in case of short-circuit condition on the dc-link.

IGBT faults may render the device either short or open. After turning on, a practical IGBT takes finite time to reach saturation voltage; meanwhile, the gate driver de-saturation detection circuit should be de-activated to avoid false fault detection. Setting a lower value of blanking time, during which de-saturation circuit is de-activated, triggers spurious fault detection [25]. A short-circuit fault in a particular IGBT can be diagnosed by applying a turn-on pulse to the complementary device and checking its $V_{C E s a t}$ fault report. The turn-on pulse must be adequately long for $V_{C E s a t}$ protection circuitry to function. It should be more than the blanking time, and short enough to keep the device junction temperature below the absolute maximum specified, $175^{\circ} \mathrm{C}$ in this case. A typical value of maximum short-circuit pulse ranges from 7.5 to $10 \mu \mathrm{s}$ for most of the IGBTs. An asserted $V_{\text {CEsat }}$ fault signal in the complementary device indicates a short-circuit fault in the IGBT under test. Setting a higher blanking time in the gate drive card results in longer fault detection time. Blanking time of $3-5 \mu$ s is a typical choice. In this work a $3.2 \mu$ s de-saturation blanking time is used.

Similarly, an open-circuit fault in a particular IGBT may be detected by applying a turn-on pulse of sufficient duration to devices and checking the corresponding line-line inverter output voltages. For example, $V_{r y}$ measured will be equal to $V_{d c}$ when top device of $R$-leg and bottom device of $Y$-leg are turned on, and a fault may be reported if the measurement reads a different value. This process may be repeated sequentially for all the semiconductor devices. Such a self-test is useful in verifying the intactness of power components before starting the intended system operation. Details of this procedure are discussed in [26]. The pre-charge and start-up diagnostics that are incorporated in the GPIS converter help improve the system reliability.

\section{Comparison with commercial IGBT stacks}

A comparison drawn between GPIS and commercial IGBT stacks in terms of key features is shown in table 2. Commercial stacks are typically available only for $50 \mathrm{kVA}$ power level and above [7-9], while the typical requirement in an academic institution is most often around $10 \mathrm{kVA}$ at graduate level [16]. 
Table 2. Comparison of GPIS with commercial IGBT stacks.

\begin{tabular}{|c|c|c|c|}
\hline Feature & GPIS power converter & Semikron PE teaching system & Methode Electronics (SPS022B3 DA120E) \\
\hline Rated power level (kVA) & 25 & 50 & 50 \\
\hline Switching frequency* & $5-70 \mathrm{kHz}$ & $20 \mathrm{kHz}(\max )$. & $10 \mathrm{kHz}(\max )$. \\
\hline De-saturation fault protection & Yes & Yes & Yes \\
\hline Over-current (OC) protection & Yes (adjustable) & No & Yes (370 A) \\
\hline Over-voltage $(\mathrm{OV})$ protection & Yes (adjustable) & No & Yes $(900 \mathrm{~V})$ \\
\hline Under-voltage (UV) protection & Yes (adjustable) & No & No \\
\hline Over-temperature cut-off & Yes & Yes & Yes \\
\hline Temperature sensing & Yes (up to 6) & No & Yes \\
\hline Shoot-through protection & Yes (adjustable) & Yes & Yes $(2 \mu \mathrm{s})$ \\
\hline Converter status communication & Yes & No & Yes \\
\hline Cooling mechanism & Forced air & Forced air & Forced air \\
\hline Fan fault detection & Yes & No & No \\
\hline Diode-bridge to dc bus & Only for pre-charge & For rated power & For rated power \\
\hline
\end{tabular}

*Power rating at $5 \mathrm{kHz}$ and $35 \mathrm{kHz}$ is $25 \mathrm{kVA}$ and $5 \mathrm{kVA}$ respectively, which has been verified experimentally.

A GPIS, however, can be appropriately designed to fit the required ratings. With the chosen state-of-the-art IGBTs and gate-drive card, the GPIS is operable up to $70 \mathrm{kH}$ switching frequency, three folds better than what is offered commercially. However, operating power level needs to be suitably de-rated to maintain device junction temperature to safe values. Also, the flexibility in the GPIS makes it feasible to fine-tune, add or disable selected features as desired, and this makes it suitable for a research laboratory environment. It may be noted that the features offered by GPIS in terms of modularity, protection, power density, compactness and performance supersede those offered by typical commercial stacks. Moreover, the details for fabrication of the GPIS stack are available in the public domain [27].

\section{Conclusion}

A GPIS design is discussed with emphasis on various auxiliary circuit functionalities that are essential for building a practical laboratory power converter. A modular design of compact PCB-mountable gate-driver card housing MOSFET-based current booster stage and $V_{C E s a t}$ protection is provided. Also, an IGBT drive circuitry best suited for discrete-IGBT-based power converter designs is explained along with a suggested PCB layout routing scheme. A tight component layout minimizes circuit parasitics and lends itself to high switching-frequency operation.

A protection scheme against excessive voltage, current or temperature excursions is discussed in the form of a state machine. A PDA card with Lattice FPGA that provides PDA functionalities is presented along with a generic nonisolated sensor-card design. Measuring range of the sensor is adequate for voltage, current and temperature up to a power level of $25 \mathrm{kVA}$ and since the card outputs unipolar signals, it may be directly interfaced with an external digital controller. Also, a start-up scheme and self-test procedure is employed that is capable of diagnosing faults in dc-link and IGBT devices with adequate coverage. A comparison with commercial IGBT stack reveals that the GPIS offers features that supersede those offered by typical commercial converter stacks. Such a GPIS built in laboratory is helpful in realizing a variety of power circuit topologies needed for research and also adds valuable hardware design and troubleshooting experience to a student working on power electronics technology.

\section{Acknowledgements}

The authors would like to thank CPRI, Ministry of Power, Government of India, under the project Power conversion, control and protection technologies for microgrid, for their financial support in this work.

\section{References}

[1] Chen Z, Guerrero J M and Blaabjerg F 2009 A review of the state of the art of power electronics for wind turbines. IEEE Trans. Power Electron. 24(8): 1859-1875

[2] Arun Karuppaswamy B, Gulur S and John V 2014 A grid simulator to evaluate control performance of grid-connected inverters. In: Proceedings of the IEEE International Conference on Power Electronics, Drives and Energy Systems (IEEE PEDES), pp. 1-6

[3] Brucchi F and Zheng F 2014 Design considerations to increase power density in welding machines converters using TRENCHSTOP 5 IGBT. In: Proceedings of the International Exhibition and Conference for Power Electronics, Intelligent Motion, Renewable Energy and Energy Management, PCIM Europe, pp. 1-8

[4] Yeh C C and Manjrekar M D 2007 A reconfigurable uninterruptible power supply system for multiple power quality applications. IEEE Trans. Power Electron. 22(4): 1361-1372 
[5] Venkatramanan D and John V 2013 Integrated higher-order pulse-width modulation filter-transformer structure for single-phase static compensator. IET Power Electron. 6(1): 67-77

[6] ON Semiconductor 2012 IGBT applications handbook HBD871/D, Rev.2

[7] IGBT Stack 2015 Datasheet of 6PS03012E33G34160. Available at: www.infineon.com

[8] SmartPower Stack 2015 Datasheet of SPSO22B3DA120E. Available at: www.methode.com

[9] Semikron IGBT Stack 2015 available at: http://www.semi kron.com/products/product-classes/stacks.html

[10] Ghoshal A and John V 2015 Active damping of LCL filter at low switching to resonance frequency ratio. IET Power Electron. 8(4): 574-582

[11] Venkatramanan D and John V 2010 A resonant integrator based PLL and AC current controller for single phase grid connected PWM-VSI. In: Proceedings of the National Power System Conference (NPSC)

[12] Iyer V M and John V 2015 Low-frequency dc bus ripple cancellation in single phase pulse-width modulation inverters. IET Power Electron. 8(4): 497-506

[13] Kulkarni A and John V 2013 Mitigation of lower order harmonics in a grid-connected single-phase PV inverter. IEEE Trans. Power Electron. 28(11): 5024-5037

[14] Kolar J W and Round S D 2006 Analytical calculation of the RMS current stress on the dc-link capacitor of voltage-PWM converter systems. IEE Proc. Electr. Power Appl. 153(4): 535-535

[15] Anand S, Singh R and Fernandes F B G 2012 Unique power electronics and drives experimental bench (PEDEB) to facilitate learning and research. IEEE Trans. Educ. 55(4): 573-579

[16] Venkataramanan D, Adapa A K and John V 2015 Design and comparative study of discrete and module based IGBT power converters. In: Proceedings of the National Power Electronics Conference

[17] Adapa A K, Venkataramanan D and John V 2015 Auxiliary subsystems of a general purpose IGBT stack for high performance laboratory power converters. In: Proceedings of the National Power Electronics Conference
[18] Adapa A K and John V 2011 Gate drive card for high power three phase PWM converters. In: Proceedings of the 5th National Power Electronics Conference

[19] Jain A K and Ranganathan V T $2011 \mathrm{~V}_{c e}$ sensing for IGBT protection in NPC three level converters-causes for spurious trippings and their elimination. IEEE Trans. Power Electron. 26(1): 298-307

[20] Datasheet of ACPL-339J 2017 Dual-output gate drive optocoupler interface with integrated $\left(V_{C E}\right)$ DESAT detection, FAULT and UVLO Status Feedback. Available at: https://docs.broadcom.com/docs/AV02-3784EN

[21] Adapa A K and John V 2011 Digital dead time logic and protection circuitry for PWM voltage source converters. In: Proceedings of the 5th National Power Electronics Conference

[22] Upamanyu K, Venkatramanan D, Adapa A and Narayanan G 2016 Experimental study on the influence of dead-time on IGBT turn-off characteristics in an inverter leg at high and low currents. In: Proceedings of the India International Conference on Power Electronics

[23] Datasheet of IKW40N120H3 2017 Rev.2.1, 2014-11-26. Available at: www.infineon.com

[24] Datasheet of B59412C1130B070 2017 PTC thermistors for overcurrent protection and as inrush current limiters. Available at: https://en.tdk.eu

[25] Venkatramanan D, Adapa A K, Upamanyu K, and John V 2016 Low current switching behavior of IGBT and associated spurious tripping in inverters employing $V_{C E}$ de-saturation protection. In: Proceedings of the International Conference on Power Electronics, Drives and Energy Systems

[26] Agrawal N 2011 Control and start-up diagnostics of three phase inverters. Master of Engineering (ME) Thesis. Department of Electrical Engineering, Indian Institute of Science (IISc). Available at: http://www.ee.iisc.ernet.in/new/ people/faculty/vjohn/stud.html

[27] Sridevi N, Venkatramanan D, Adapa A K and John V 2017 Building block for power electronic energy conversion using general purpose IGBT stack for educational purpose. Available at http://cce.iisc.ernet.in/cdc.html 